\title{
Series-Parallel Connected Capacitor Type Boost Converter for a Single-Phase SRM
}

\author{
Dong-Hee Lee*, Jiang Liang*, and Jin-Woo $\mathrm{Ahn}^{\dagger}$ \\ $\dagger *$ Dept. of Mechatronics Engineering, Kyungsung University, Busan, Korea
}

\begin{abstract}
An active boost converter for a single phase SRM using series-parallel connected capacitors is proposed in this paper. The proposed active boost converter has two diodes and one power switch with an anti-parallel diode and one additional boost capacitor. The additional boost capacitor could be series or parallel connected to the dc-link capacitor to produce proper excitation and demagnetization voltage. The proposed active boost converter can easily achieve a fast excitation and demagnetization from the capacitor connection. In this paper, series and parallel connected converters are reviewed, and the detailed operating modes as well as the voltage characteristics of the proposed converter are analyzed. The simulation and experimental results shows the effectiveness of the proposed active boost converter.
\end{abstract}

Key Words: Active boost converter, Hybrid-connected capacitor, SRM(Switched Reluctance Motor)

\section{INTRODUCTION}

A SRM (switched reluctance motor) is a low cost, simple and robust structure with high power density, reliability, controllability and intense temperature variations. A single phase SR drive has a low cost, and is suitable for high speed applications [1]. However, the terminal voltage of the motor windings is also limited by the input source voltage in a conventional SR drive. In high speed operation, suitable pulse wave current control is very difficult due to the short duration of excitation and demagnetization. Though the turnon angle and turn-off angle can be regulated to improve some of its demerits, the additionally extended excitation region still brings on additional loss and more negative torque, which reduce the output torque and efficiency.

For these reasons, many boost converters have been proposed in the past few years [2]-[11]. They can be divided into two types: a passive boost and an active boost converter. The passive boost converter has a simple structure and low cost, but the boost voltage cannot be controlled [3]-[7]. The major advantage of an active boost converter is a controllable boost voltage by an additional power switch. Series and parallel connected capacitor circuits for active boost converters were proposed in [11]. Fast excitation and demagnetization mode can be obtained in these two converters. In order to cover a wide operation range, the active power switch should be a control to keep a stable voltage.

In this paper, an active boost converter for a single phase SRM using series-parallel connected capacitors is proposed.

Manuscript received Nov. 23, 2009; revised May 8, 2010

$\dagger$ Corresponding Author: jwahn@ks.ac.kr

Tel: +82- 51-620-4773, Fax: +82- 51-624-5980, Kyungsung Univ.

* Dept. of Mechatronics Engineering, Kyungsung University, Korea
The proposed active boost circuit is made up of two additional diodes, one power switch and one boost capacitor. The additional boost capacitor can be connected to the dc-link capacitor in series or parallel according to the additional active power switch. From the series connection of the two capacitors in the excitation region, high boost voltage can be supplied to the phase winding for a fast building up of the excitation current. Furthermore, a high negative bias can be obtained in the demagnetization region. These additional boost voltage modes can reduce the negative torque and the advance angle and the output power of the motor.

In order to compare the previous studies, conventional converters for single phase SRMs are reviewed. The operating modes and voltage characteristics of the proposed active boost converter are explained in detail. Practical experimental results show the effectiveness of the proposed power converter for single phase SRMs.

\section{REVIEW OF SINGLE PHASE SR DRIVES}

\section{A. Conventional Single phase SR drive}

Fig. 1 shows the operating modes of a conventional asymmetric converter for a single phase SRM. Two power switches and diodes are connected to the motor winding. The asymmetric converter can supply dc-link voltage in the excitation mode, zero voltage in the free-wheeling mode and negative dc-link voltage in the demagnetization mode as shown in Fig. 1.

The asymmetric converter is very simple and popular, but the excitation and demagnetization voltages are determined by the source input voltage. This voltage condition restricts the dynamics of the current control and the torque generation region to avoid negative torque. In order to get an ideal 


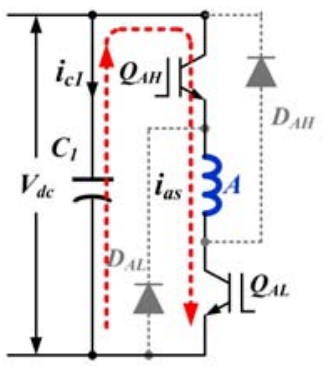

(a) Excitation mode.

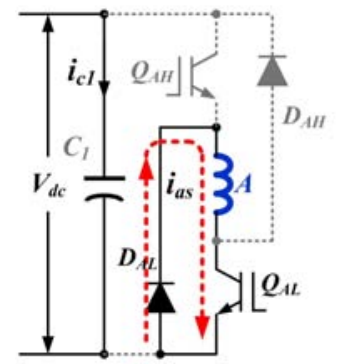

(b) Output current control.



(c) Output current control.

Fig. 1. Operation modes of an asymmetric converter.

square-wave phase current in the proper torque region, a high boost voltage is essential in the excitation and demagnetization modes.

\section{B. Active Boost Converter using Series Connected Capacitors}

In order to improve the dynamics of current control, an additional power circuit is added. Boost converters and buckboost converters are good ways to increase the active voltage of phase windings.

In order to implement boost and buck-boost converters, additional power components, such as power switches, diodes, reactors and capacitors are required. However, a power circuit with additional reactors increases the system size, and the manufacturing effort. Fig. 2 shows a 4-level converter and its operating modes for a high speed SRM [11]. In this converter, the boost capacitor saves the demagnetized energy and the dc-link capacitor is connected in series.

In order to avoid short circuits, the diode $D_{1}$ is connected. The operation modes of this converter are divided into 4 modes: fast excitation mode, normal excitation mode, freewheeling mode and fast demagnetization mode as shown in Fig. 2. In the fast excitation and fast demagnetization modes, the boost and dc-link capacitors are series connected, so that high positive excitation and high negative voltage can be supplied to the phase winding. As a result, the excitation and demagnetization time can be reduced, and the power of the motor can be increased. However, the additional components increase the cost of the converter. In addition, the voltage rating of the power component should be increased due to the boost voltage of the 4-level converter. In order to avoid overcharging of the boost capacitor, the controller should adjust the boost voltage to keep it at a suitable level.

Fig. 3 shows the voltage characteristic of a boost capacitor in the fixed recovery energy. When the discharge time of

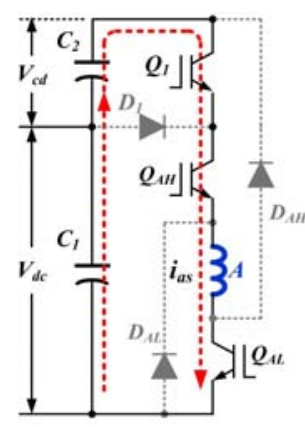

(a) Excitation mode.

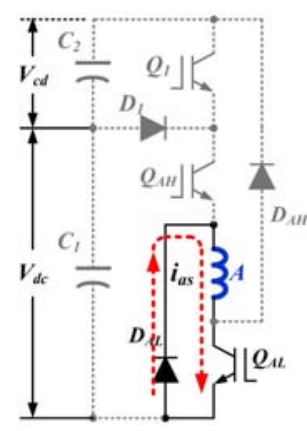

(c) Output current control.

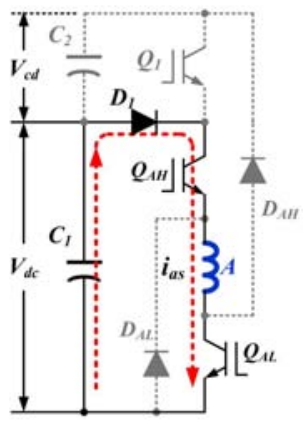

(b) Output current control.

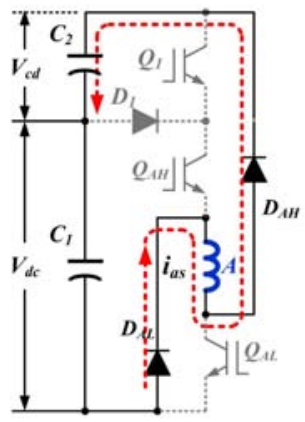

(d) Output current control.
Fig. 2. Operation modes of a 4-level converter.

the boost capacitor decreases, the boost voltage exponentially increases. Furthermore, the increasing slope is inversely proportional to the boost capacitor. In an ideal case, the boost voltage can be increased infinitely. However, the voltage rate of the power devices and the motor should be considered.

\section{Active Boost Converter using Parallel Connected Capaci- tors}

An active boost converters using parallel connected capacitors has been proposed [6]. Fig. 4 and Fig. 5 show the structure and operating modes of an active boost converter using parallel connected capacitors, respectively. The active boost power switch controls the discharge time of the boost capacitor. As a result, each capacitor can supply source power to the phase winding independently. However, the supplied voltage to the phase winding is dependent on the charged boost capacitor voltage.

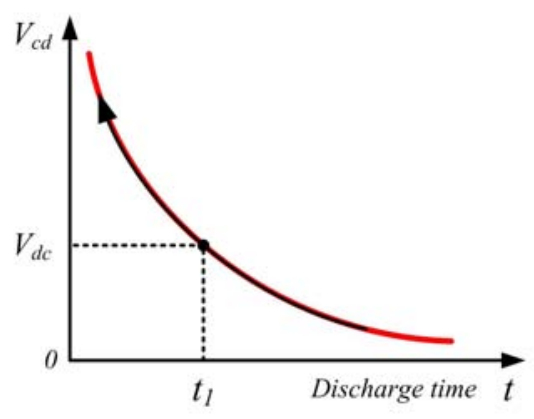

Fig. 3. Simplified circuit of rectifier for digital load. 
The operation mode of a parallel connected capacitor converter is divided into 5 modes as shown in Fig. 5. These include the fast excitation mode, normal excitation mode, free-wheeling mode, fast demagnetization mode and the boost capacitor charging at start-up. In the fast excitation mode, the active switch is turned on, and the high voltage of a boost capacitor makes the diode D1 turn off. As a result, the high charged voltage can be applied to the phase winding and build the excitation current quickly. In the fast demagnetization mode, the recovery energy, which is determined by the demagnetized current, is only charged to the boost capacitor. In the boost capacitor charging at start-up, the dc-link voltage is charged to the boost capacitor to be ready for the fast excitation mode.

Fig. 6 shows the boost voltage characteristics according to discharge time in the fixed recovery energy. After the boost capacitor is charged at start-up, the voltage of the boost capacitor is higher than or equal to the dc-link voltage. The voltage rating of the boost capacitor is higher than that of a 4-level converter.

\section{PROPOSED ACTIVE BOOST CONVERTER FOR A SINGLE PHASE SRM}

\section{A. Boost Converter with Hybrid Connected Capacitors}

In order to combine the advantages of series-connected capacitors and parallel-connected capacitors, a novel active boost converter with hybrid-connected capacitors is proposed. Fig. 7 shows the proposed active boost converter for single phase SRMs. At the front-end, a novel active boost circuit is designed with two diodes, capacitors and one power switch with an anti-parallel diode. The diode D2 and power switch Q1 can be found in a package commercially.

Fig. 8 shows the operating modes of the proposed active boost network. The proposed active boost network has four operating modes. These include input mode 1 , input mode 2 , output mode 1 and output mode 2 . In input mode 1 , the dc source charges the dc-link capacitor $C_{1}$ from the $a b$ terminal directly, so that the voltage of the dc-link capacitor $C_{1}$ always keeps the balance with the dc source. However, the dc source cannot charge the boost capacitor $C_{2}$, because of the diode $D_{3}$.

In input mode 2, the energy flows from the $c d$ terminal which is connected to the motor winding. The recovery energy from the motor winding is charged to capacitor $C_{1}$ and $C_{2}$ through the diode $D_{2}$ as shown in Fig. 8(b).

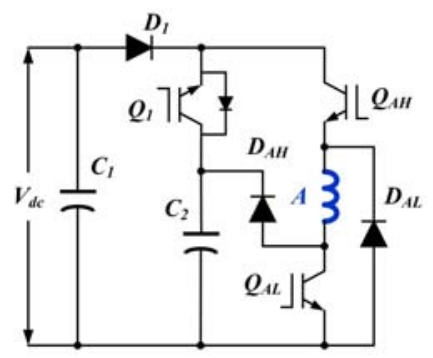

Fig. 4. Active boost converter using parallel connected capacitors.

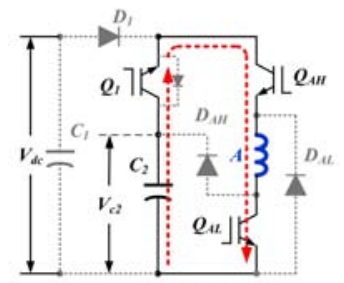

(a) Fast excitation.



(c) Free-wheeling.

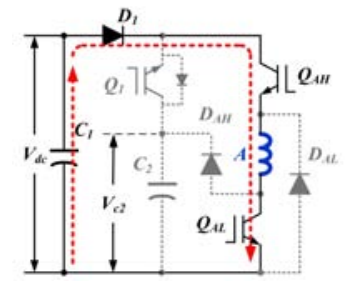

(b) Excitation.

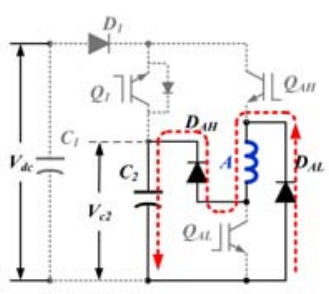

(d) Fast demagnetization.



(e) Boost capacitor charge at start-up.

Fig. 5. Operation modes of parallel connected capacitors.

In output mode 1, the two capacitors and diodes compose the two independent voltage sources in parallel as shown in



Fig. 6. Characteristic of boost capacitor voltage.

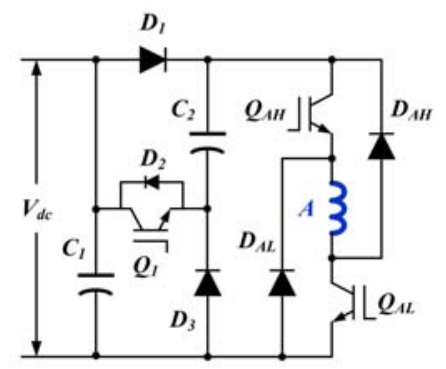

Fig. 7. Proposed boost converter with hybrid connected capacitors. 


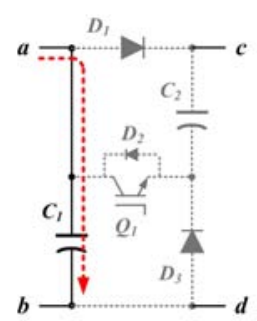

(a) Input mode 1 .

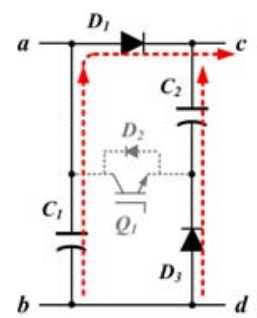

(c) Output mode 1 .



(b) Input mode 2.

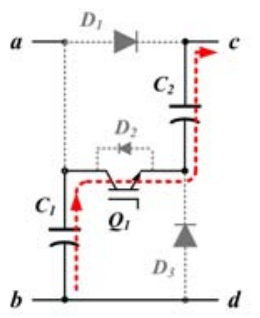

(d) Output mode 2.
Fig. 8. Operation modes of the proposed converter.

Fig. 8(c).

The diode $D_{2}$ is turned off, but one or both of the diodes $D_{1}$ and $D_{3}$ will be turned on. As a result, the energy is supplied from one or both capacitors which are determined by each voltage. The output voltage of the $c d$ terminal is equal to their maximum voltage. In this mode, owing to its parallel structure, the boost capacitor cannot be overcharged. If the ripple of the dc-link is neglected, the voltage of the boost capacitor $C_{2}$ is automatically the same as the dc-link voltage. In output mode 2 , the active switch $Q_{1}$ is turned on, and the three diodes are all turned off due to the reverse direction of the current. It is easy to see that the positive of the dc-link capacitor $C_{1}$ is connected to the negative of the boost capacitor $C_{2}$ by the switch $Q_{1}$. The two capacitors are connected in series as shown in Fig. $8(d)$. The output voltage of the $c d$ terminal is the superposition voltage of them. Although the dc-link capacitor $C_{1}$ is always fixed by the dc-source, the voltage of the boost capacitor $C_{2}$ reduces the energy output. If this capacitor is overcharged, its voltage will drop under the dc link voltage. As a result, the turn-on time of the active switch should be a control to obtain a steady voltage.

\section{B. Operation of a Single Phase SRM}

Fig. 9 shows the operation modes of the proposed converter in a single phase SRM. It has six modes which include boost capacitor excitation mode, dc-link capacitor excitation mode, two capacitor excitation mode, fast excitation mode, freewheeling mode and fast demagnetization mode.

The boost capacitor excitation mode shown in Fig. 9(a) uses the charged boost capacitor voltage to excite the phase winding. If the boost capacitor voltage is higher than the dclink voltage, the diode D1 is disconnected. As a result, the boost capacitor voltage is discharged to the phase winding. If the boost capacitor voltage is lower than the dc-link voltage, the dc-link capacitor excitation mode is operated as shown in Fig. 9(b).

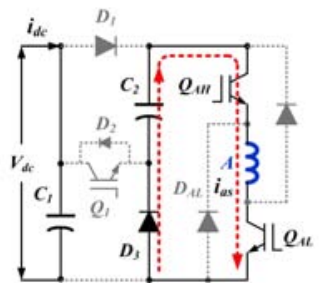

(a) Boost capacitor excitation.

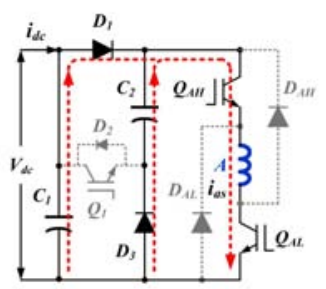

(c) Two capacitors excitation.



(e) Free-wheeling

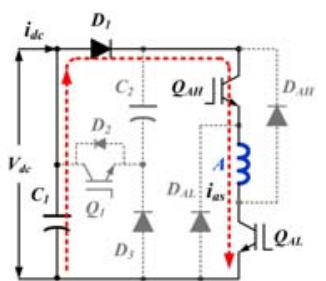

(b) Dc-link capacitor excitation.



(d) Fast excitation.



(f) Fast demagnetization.
Fig. 9. Operation modes of proposed converter for single phase SRM.

The phase winding is excited by the dc-link capacitor voltage. If the voltages of the two capacitors are same, the phase winding is excited by the two capacitor's voltages shown in Fig. 9(c).

In order to get a high excitation voltage, the active power switch $Q_{1}$ is turned on. The series connected capacitors can supply a high excitation voltage due to the summation of the dc-link and boost voltage shown in Fig. 9(d). The freewheeling mode shown in Fig. 9(e) is the same as the one in a conventional converter. When the power switches are all turned off, the recovery energy of the phase winding is stored in the boost capacitor and dc-link capacitor through the anti-parallel connected diode shown in Fig. 9(f).

Table I shows the summarized characteristics of the proposed active boost converter. In Table I, $V_{Q}$ and $V_{D}$ are the voltage drops of the power switch and the diode, respectively.

TABLE I

THE OPERATION MODES OF PROPOSED CONVERTER

\begin{tabular}{cccc}
\hline \hline $\begin{array}{c}\text { Operating } \\
\text { Mode }\end{array}$ & $\begin{array}{c}\text { Active } \\
\text { Switch }\end{array}$ & $\begin{array}{c}\text { Voltage } \\
\text { condition }\end{array}$ & $\begin{array}{c}\text { Phase } \\
\text { Voltage }\end{array}$ \\
\hline Excitation-1 & off & $V_{C 1}<V_{C 2}$ & $V_{C 2}-V_{D}-2 V_{Q}$ \\
Excitation-2 & off & $V_{C 1}>V_{C 2}$ & $V_{C 1}-V_{D}-2 V_{Q}$ \\
Excitation-3 & off & $V_{C 1}=V_{C 2}$ & $V_{C 2}-V_{D}-2 V_{Q}$ \\
Excitation-4 & on & & $V_{C 1}-V_{C 2}-3 V_{Q}$ \\
Free-wheeling & off & & $-\left(V_{D}+V_{Q}\right)$ \\
Demagnetization & off & & $-\left(V_{C 1}+V_{C 2}+3 V_{D}\right)$ \\
\hline \hline
\end{tabular}

Fig. 10 shows the phase voltage and phase current wave- 
forms according to the active power switch $Q_{1}$ state. When the switch $Q_{1}$ turns off, the operating mode is the same as in an asymmetric converter due to the parallel connected capacitors. When the switch $Q_{1}$ turns on, the two capacitors are connected in series, and the high excitation voltage makes the fast excitation current. As a result, the phase current can be built up quickly, and the advance angle can be reduced. The fast excitation current can also be used to improve the dynamic performance. If the same advance angle is used, more excitation current can be established. In high speed operation, when compared with a conventional SR drive, fast excitation and fast demagnetization can improve the power and efficiency.

Fig. 11 shows the boost capacitor voltage characteristics of the proposed active boost converter in fixed recovery energy. The voltage curve is separated into two parts. If the discharging energy is smaller than the recovery energy, the voltage of the boost capacitor keeps a constant value which is the same as the dc-link voltage during 0 to $t_{1}$.

The two capacitors are parallel connected, and the overcharge energy can be discharged automatically with a short discharge time. If the discharge time is increased, the boost capacitor voltage will be under the dc-link voltage. Therefore, this region is similar to a two capacitor series-connected converter.

Table II shows the summarized characteristics of the 4 types of power converter for a single phase SRM. Even though the series-connected type and the parallel type can obtain higher boost voltage than the proposed converter, the higher boost voltage increased the voltage rating of the capacitor and the power devices, which results in a higher cost. In the proposed converter, the boost voltage can be stably limited to the dc-link capacitor voltage. Also fast excitation and demagnetization control can be implemented with lower voltage rating power devices.
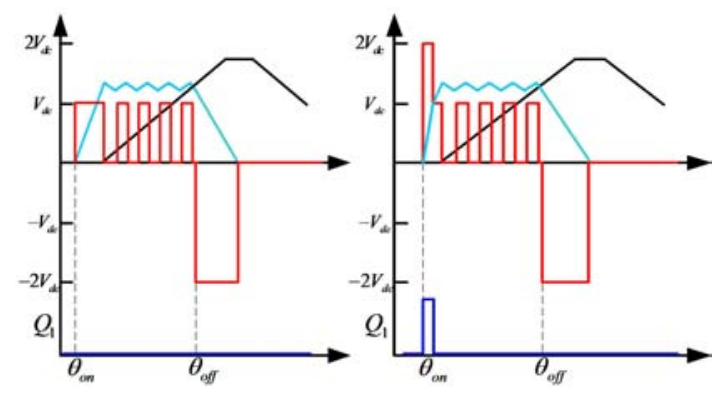

Fig. 10. Phase voltage and phase current waveform.

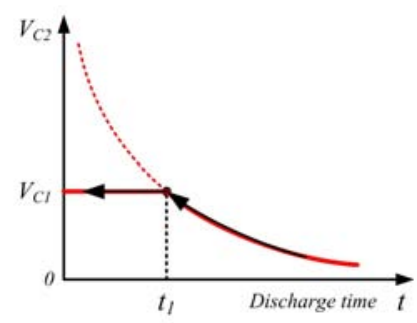

Fig. 11. Boost voltage characteristic in the proposed converter.
TABLE II

THE COMPARISONS OF THE 4 TYPES POWER CONVERTER FOR SINGLE PHASE SRM

\begin{tabular}{ccccc}
\hline \hline contents & Asymmetric & series type & $\begin{array}{c}\text { parallel } \\
\text { type }\end{array}$ & $\begin{array}{c}\text { Proposed } \\
\text { type }\end{array}$ \\
\hline Maximum voltage & $V_{d c}$ & $2 V_{d c} \sim \infty$ & $2 V_{d c} \sim \infty$ & $2 V_{d c}$ \\
Fast excitation & No & Yes & Yes & Yes \\
Voltage rate & $V_{d c}$ & $V_{d c} \sim \infty$ & $2 V_{d c} \sim \infty$ & $V_{d c}$ \\
power switches & 2 & 3 & 3 & 3 \\
Diodes & 2 & 3 & 3 & 4 \\
Stability & Good & Normal & Normal & Good \\
\hline \hline
\end{tabular}

\section{SIMULATION AND EXPERIMENTAL RESULTS}

In order to verify the performance of the proposed converter, the operating characteristics of various converters are simulated. Fig. 12 shows the comparative simulation results for three types of active boost converters. In this simulation, the dc-link is connected to an ideal dc source $100\left[V_{d c}\right]$, and the capacitance of the boost capacitor is big enough to reduce the voltage ripple. Due to the hysteresis control, the current is flat, but if boost voltage is applied, the switching is higher than in the conventional case. As discussed before, the voltage of the boost capacitor is higher in the two capacitor parallelconnected converter.

Fig. 13 shows the experimental configurations. The digital controller is designed with a TMS320F2812 DSP, while embedded $\mathrm{AD}$ converter modules are used for the detection of phase current, dc-link and boost capacitor voltages. The hysteresis current control scheme, which has a $25[/ \mathrm{mus}]$ sampling time, is implemented. A 6/6 single phase SRM, which has a 78[V] rated voltage, is used for the experiments.

Fig. 14 shows comparative experimental results for the three types of boost converters at 4,000[rpm]. The dwell angle, turn-on and turn-off angles are set to the same condition. In order to maintain a constant boost voltage, the active power switches are is controlled in the series and parallel connected boost converters. The charged current of the boost capacitor is changed a lot with high ripple shown in Fig. 14(a) and (b). Furthermore, the boost voltage is doubly high in the parallel connected power converter. However, the boost capacitor voltage is very stable in the proposed converter as shown in Fig. 14(c).

Fig. 15 shows the experimental results at 5,000[rpm] with angle position control. The fast excitation and demagnetization can be seen in these results. The results are almost the same due to the same boost voltage.

Fig. 16 shows the experimental results of the proposed converter according to the active power switch state. The voltage of the boost capacitor automatically stays at a constant value. When the active power switch turns off, the fast excitation disappears as seen in Fig. 16(a). However, fast demagnetization is obtained by the two series-connected capacitors. Some recovery energy is stored in the boost capacitor. When the voltage of the boost capacitor is higher than the dc link, the boost capacitor starts to discharge. In an ideal case, the charging current and discharging current are a formal resemblance. However, the discharging current is anomalous in this experiment. On a large time scale, the waveform of the discharging current present 2 times the line frequency. 


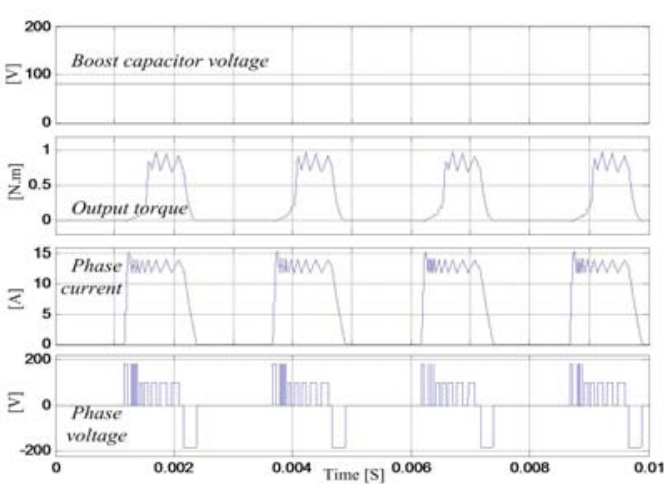

(a) Two capacitors series-connected converter.

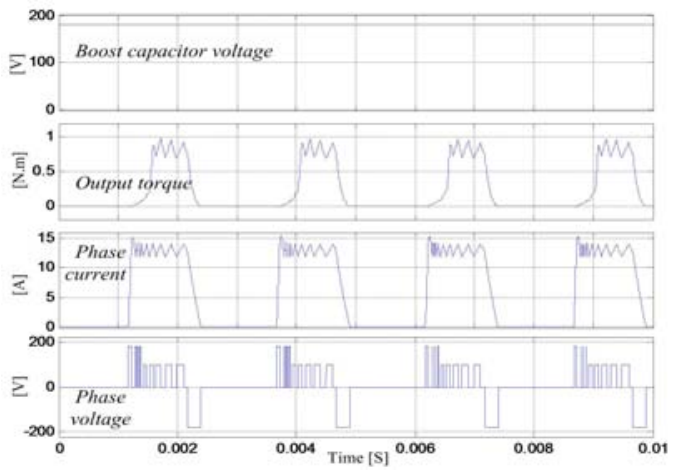

(b) Two capacitors parallel-connected converter.

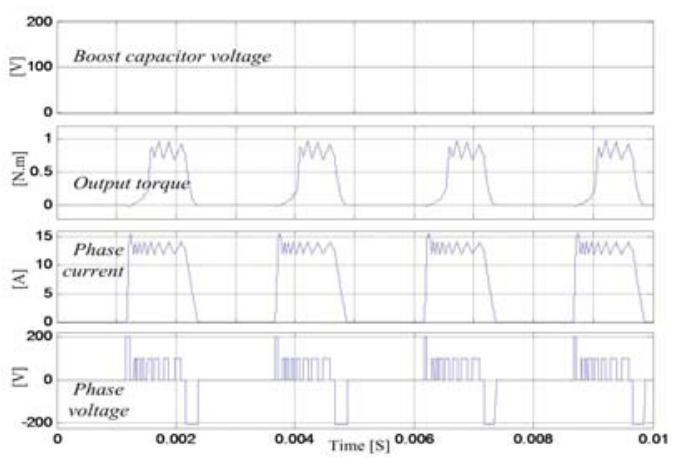

(c) The proposed converter.

Fig. 12. Simulation results of three types of active boost converter.

The reason is that the voltage of the boost capacitor must follow the voltage ripple of the dc-link when the two capacitors

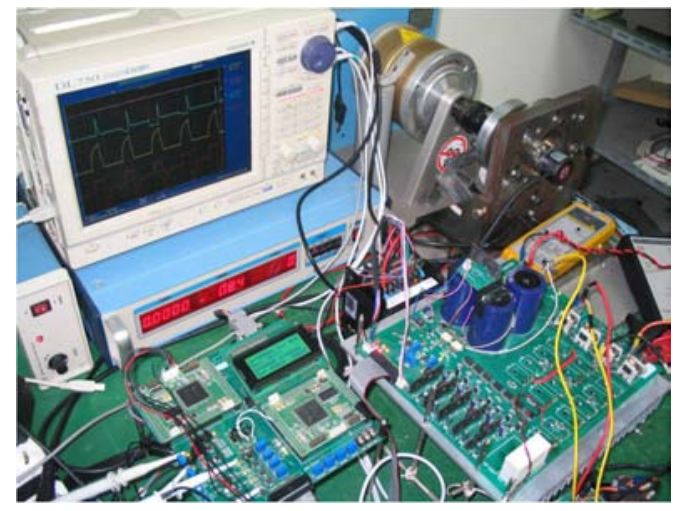

Fig. 13. Experimental configurations.

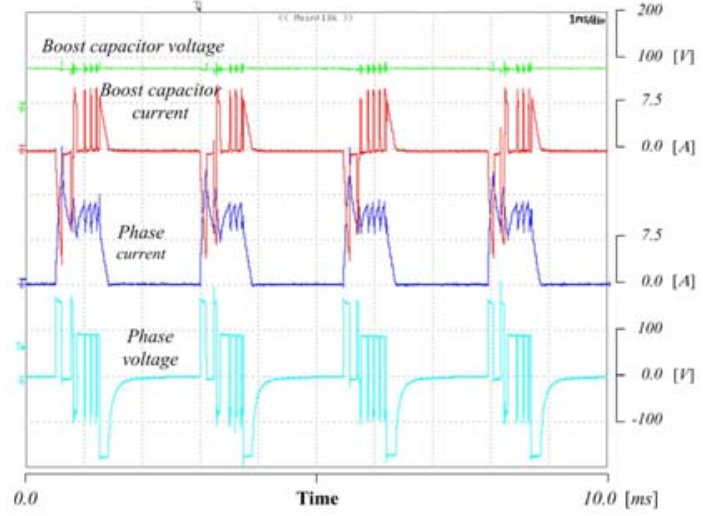

(a) Series-connected converter.

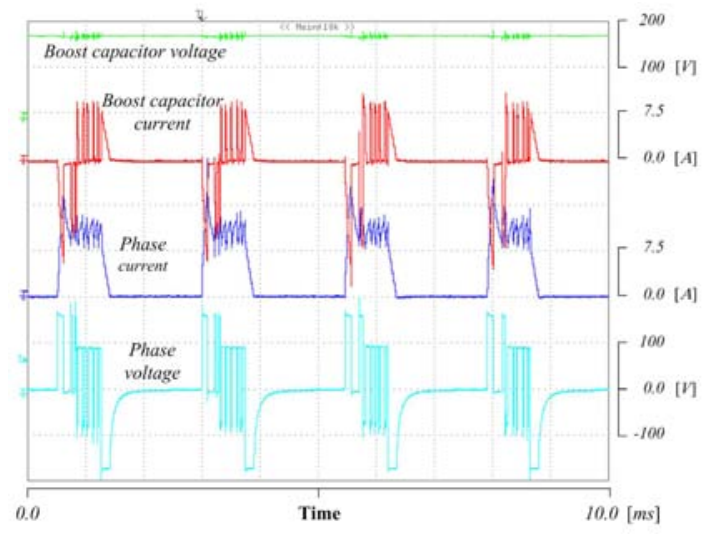

(b) Parallel-connected converter.

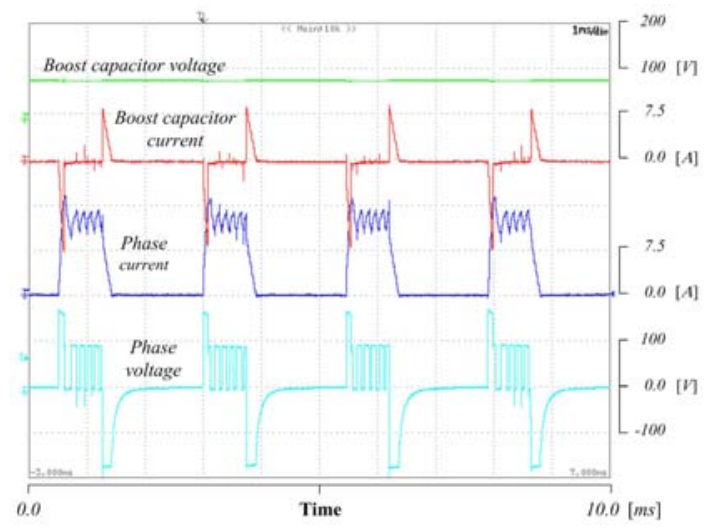

(c) Proposed hybrid-connected converter.

Fig. 14. Compared experimental results in the current control.

are connected in parallel. Although the ripple voltage is very small, the discharging current can verify this relationship. When the switch is turned on, the two capacitors are connected in series, the high voltage is supplied, and the fast excitation current is obtained as shown in Fig. 16(b). Since only a part of the recovery energy is discharged in the fast excitation mode, the rest of the energy should be discharged in the boost capacitor excitation mode.

\section{CONCLUSIONS}

In this paper, an active boost converter for single phase SRMs using two hybrid-connected capacitors is proposed. 




(a) Series-connected converter.

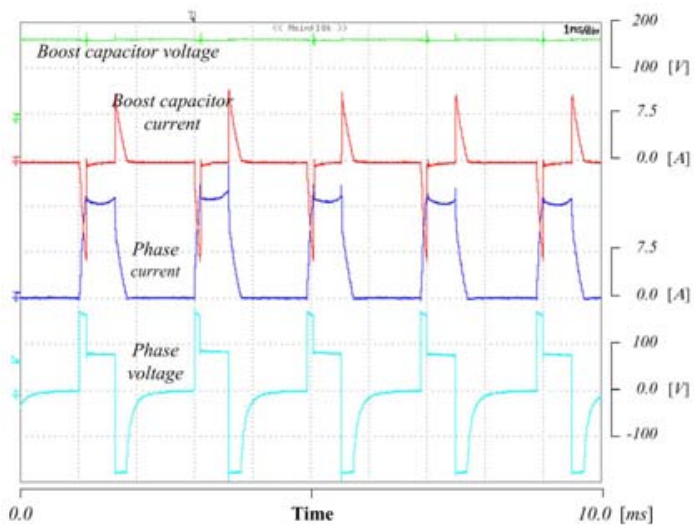

(b) Parallel-connected converter.

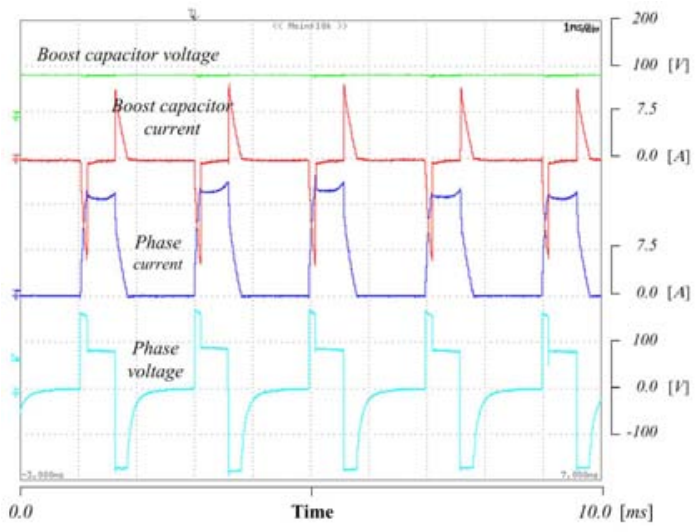

(c) Proposed hybrid-connected converter.

Fig. 15. Compared experimental results in the dwell angle control.

The proposed active boost converter has additional operating modes for improving the performance with a low voltage rate boost capacitor. In addition, the boost capacitor voltage can be automatically limited to the dc-link capacitor voltage. According to the active power switch control, a fast excitation and dc-link voltage excitation can be selected with the high negative demagnetization mode. If an active power switch with an anti-parallel diode is selected, a more stable and reasonably priced drive than a series or parallel capacitor connected power converter can be implemented for a single phase SRM. In a comparison of the simulations and experiments, the proposed converter shows stable operating characteristics with fast exci-

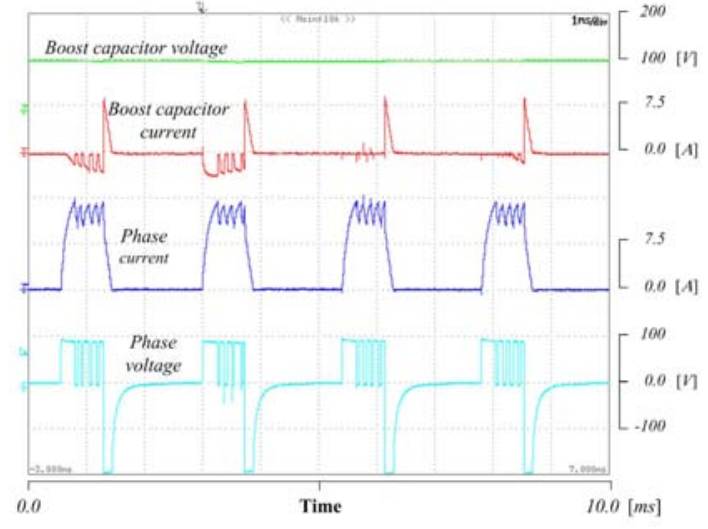

(a) turn-off $Q_{1}$.

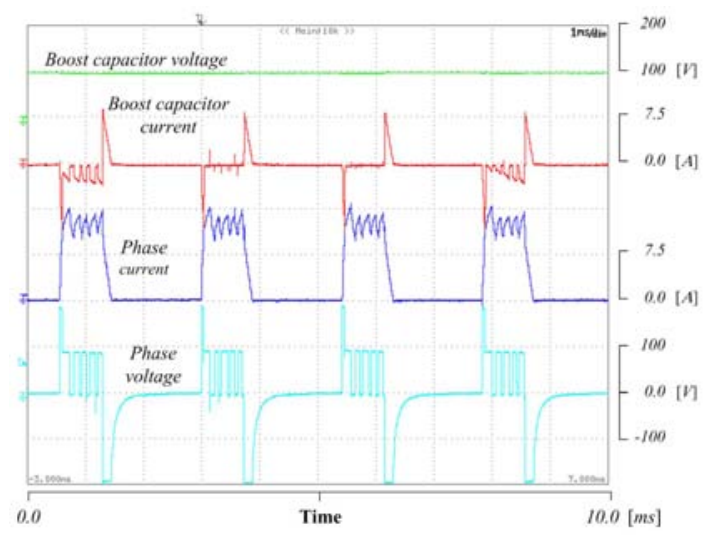

(b) turn-on $Q_{1}$.

Fig. 16. Experimental results of proposed converter according to the power switch.

tation and fast demagnetization. Furthermore, the boost voltage can be automatically controlled.

\section{ACKNOWLEDGMENT}

This work is the outcome of a Manpower Development Program for Energy \& Resources supported by the Ministry of Knowledge and Economy (MKE).

\section{REFERENCES}

[1] R. Krishnan, Switched Reluctance Motor Drives: Modeling, Simulation, Analysis, Design, and Applications, CRC Press, 2001.

[2] A.K. Jain, N. Mohan, "SRM power converter for operation with high demagnetization voltage," Industry Applications, IEEE Transactions on, Vol. 41, Issue 5, Sep./Oct. pp. 1224 - 1231, 2005.

[3] A. Dahmane, F. Meebody, F.-M. Sargos, "A novel boost capacitor circuit to enhance the performance of the switched reluctance motor," Power Electronics Specialists Conference, pp. 844 - 849, 17-21 Jun. 2001.

[4] S. Chan, H. R. Bolton, "Performance enhancement of single-phase switched-reluctance motor by DC link voltage boosting," Electric Power Applications, IEE Proceedings B Vol 140, Issue 5, Vol.2, pp. 316 - 322, Sep.1993.

[5] K. I. Hwu, C. M. Liaw, "DC-link voltage boosting and switching control for switched reluctance motor drives," Electric Power Applications, Vol. 147, Issue 5, pp. 337 - 344, Sep. 2000.

[6] J. D. Lewis, H. R. Bolton, and N. W. Phillips, "Performance enhancement of single and two phase SR drives using a capacitor boost circuit," in European Power Electronics and Applications Conf. Rec., Vol. 3, pp. 229-232, 1995.

[7] G. Dessouky, B. W. Williams, and J. E. Fletcher, "A novel power converter with voltage boosting capacitors for a four-phase SRM drive," IEEE Trans. Ind. Electron., Vol. 45, No. 5, pp. 815-823, Oct. 1998. 
[8] S. Chan and S. R. Bolton, "Performance enhancement of single-phase switched-reluctance motor by dc link voltage boosting," Proc. IEE-Elect. Power Appl., Vol. 140, No. 5, pp. 316-322, Sep. 1993.

[9] S. Mir, I. Husain, and M. E. Elbuluk, "Energy-efficient c-dump convertersfor switched reluctance motors," IEEE Trans. Power Electron., Vol. 12, No. 5, pp. 912-921, Sep. 1997.

[10] A. M. Hava, V. Blasko, and T. A. Lipo, "A modified c-dump converterfor variable-reluctance machines," IEEE Trans. Ind. Appl., Vol. 28, No. 5, pp. 1017-1021, Sep./Oct. 1992.

[11] J. N. Liang, Z. G. Lee, D. H. Lee, J. W. Ahn, "DITC of SRM Drive System Using 4-Level Converter," Proceedings of ICEMS 2006, Vol. 1, 21-23 Nov. 2006.

[12] Krishnan, R., "A novel converter topology for switched reluctance motor drives," Conf. Rec., IEEE PESC, Baveno, Italy, pp. 1811-1816, 23-27 Jun., 1996.

[13] Y. H. Kim, "Converter Coupled Finite Element Analysis of Single Phase Switched Reluctance Motor," Journal of Electrical Engineering and Technology, Vol. 2, No. 2, pp. 216-220, Jun. 2007.

[14] Maged, N. F. Nashed, "Simulation and Experimentals of a Bi-Directional Converter with Input PFC on SRM System," Journal of Power Electronics, Vol. 6, No. 2, pp. 121-130, Apr. 2006.

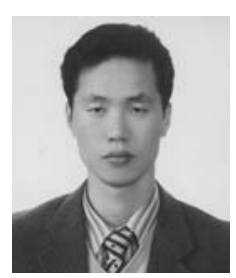

Dong-Hee Lee was born on November 11, 1970 and received his B.S, M.S., and Ph.D. in Electrical Engineering from Pusan National University, Busan, Korea, in 1996, 1998 and 2001, respectively. He worked as a Senior Researcher of the Servo R\&D Team at OTIS-LG, from 2002 to 2005. He has been an Assistant Professor in the Department of Mechatronics Engineering, Kyungsung University, Busan, Korea, since 2005. His major research interests are in the areas of servo systems and electrical motor drives with power electronics.

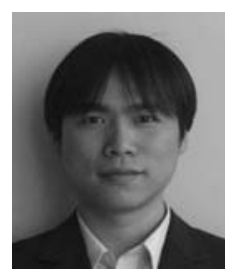

Jiang Liang received his B.S degree in Electrical Engineering and Automation from Shenyang University of Technology, Shenyang, China, in 2003. He received his M.S in Electrical and Electronics Engineering, and his $\mathrm{Ph}$. D degree in Industrial and Systems Engineering, from Kyungsung University, Busan, Korea, in 2007 and 2010 , respectively. He is currently working in Shenzhen Institutes of Advanced Technology, Chinese Academy of Sciences as research associate. His current research interests include advanced motor drive system and power converter.

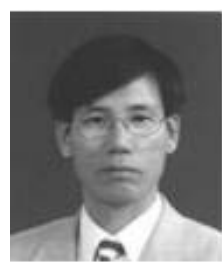

Jin-Woo Ahn was born in Busan, Korea, in 1958. He received his B.S., M.S., and Ph.D. in Electrical Engineering from Pusan National University, Pusan, Korea, in 1984, 1986, and 1992, respectively. He has been with Kyungsung University, Busan, Korea, as a Professor in the Department of Electrical and Mechatronics Engineering since 1992. He was a Visiting Researcher in the Dept. of ECE and Speed Lab, Glasgow University, U.K., and a Visiting Professor in the Dept. of ECE and WEMPEC, UW-Madison, USA. He also visited in the Dept. of ECE, Virginia Tech. as a Visiting Professor from July 2006 to July 2007. He has been the Director of the Advance Electric Machinery and Power Electronics Center since 2005. Dr Ahn is the author of five books including SRM. He is also the author of more than 100 papers, and has several patents. His current research interests are in the areas of advanced motor drive systems and electric vehicle drives. Dr. Ahn has received several paper awards including the Best Paper Award from the Korean Institute of Electrical Engineers and the Korean Federation of Science and Technology Society in 2003, respectively. He is a senior member of the Korean Institute of Electrical Engineers, a member of the Korean Institute of Power Electronics and a senior member of IEEE. 